\title{
Analisis Pengaruh Kerja Lembur terhadap Produktivitas Tenaga Kerja Konstruksi pada Pekerjaan Struktur Bawah
}

\author{
WANDA KURNIAWAN, AFRIZAL NURSIN \\ Jurusan Teknik Sipil, Politeknik Negeri Jakarta, Indonesia \\ Email: wanda.kurniawan.ts17@mhsw.pnj.ac.id
}

\begin{abstract}
ABSTRAK
Produktivitas tenaga kerja merupakan salah satu faktor penentu keberhasilan sebuah proyek. Salah satu cara untuk mempercepat durasi proyek dengan menerapkan jam kerja lembur. Tujuan penelitian untuk menjabarkan produktivitas pada jam kerja normal dan lembur serta faktor yang mempengaruhi produktivitas lembur. Metode pengumpulan data dilakukan dengan pengamatan di lapangan. Hasil penelitian didapatkan produktivitas pekerjaan tiang pancang jam normal 3,489 $\mathrm{m}^{\prime} /$ manhours dan 3,941 $\mathrm{m}^{\prime} /$ manhours jam lembur; produkivitas pekerjaan pembesian capping beam pada jam normal 8,610 kg/manhours dan 12,415 kg/manhours jam lembur; pekerjaan bekisting jam normal 0,462 $\mathrm{m}^{2} /$ manhours dan 0,763 $\mathrm{m}^{2} /$ manhours jam lembur; pekerjaan pengecoran normal $0,170 \mathrm{~m}^{3} /$ manhours. Performa proyek dihitung menggunakan rumus indeks produktivitas dan menghasilkan angka > 1 artinya cukup baik, pekerjaan pengecoran memiliki performa yang kurang baik karena nilai indeks produktivitas < 1. Hasil kuesioner menggunakan metode RII didapatkan sepuluh faktor yang mempengaruhi produktivitas lembur pada struktur bawah, diantaranya variabel faktor lingkungan, pengalaman kerja, metode kerja, keselamatan kerja dan variabel material dan alat.
\end{abstract}

Kata kunci: kerja lembur, kerja normal, produktivitas, relative importance index

\begin{abstract}
Labor productivity is one of the determining factors in the success of a project. There is one way to accelerate the project forward is to apply overtime hours. This research intends to describe the productivity during normal working hours and overtime hours, as well as the factors that affect the overtime productivity. The method of data collection was carried out by site observations. The results of the research on the productivity of pile work at normal hours are $3.489 \mathrm{~m}^{\prime} /$ manhours and $3.941 \mathrm{~m} /$ manhours at overtime hours, the productivity of reinforcing capping beam work at normal hours is $8.610 \mathrm{~kg} /$ manhours and $12.415 \mathrm{~kg} /$ manhours at overtime hours, formwork work normal hours is $0.462 \mathrm{~m}^{2} /$ manhours and $0.763 \mathrm{~m}^{2} /$ manhours of overtime hours, the normal rate is $0.170 \mathrm{~m}^{3} /$ manhours. The project performance is calculated with the formulation of the productivity index and the result should be more than $1(>1)$, which means achieved is quite good. Casting work's performance is not really good enough, because the index number is less than $1(<1)$. The results of the questionnaire using the Relative Importance Index Method obtains ten factors that affect overtime productivity in lower structure, those are environmental factors variable, work experience, work methods, health and safety environment, as well as material and equipment variables.
\end{abstract}

Keywords: work overtime, normal work, productivity, relative importance index

RekaRacana - 120 


\section{PENDAhULUAN}

Pekerjaan yang tidak didukung dengan sumber daya manusia yang baik dari segi kualitas dan produktivitas tidak akan memdapatkan hasil yang maksimal serta memuaskan dalam proyek konstruksi. Penggunaan sumber daya manusia yang tidak tepat juga dapat menyebabkan kerugian proyek konstruksi. Sumber daya manusia merupakan salah satu faktor penentu keberhasilan proyek konstruksi, serta penunjang manajemen dan produktivitas tenaga kerja (Hasanah et al., 2017).

Wakil Presiden K.H. Ma'ruf Amin menilai produktivitas tenaga kerja di Indonesia saat ini belum yang terbaik. "Salah satu ciri SDM yang unggul adalah tingkat produktivitasnya. Tapi kalau bicara produktivitas, khususnya produktivitas pekerja konstruksi, Indonesia bukan yang terbaik di ASEAN (Deni, 2020). Persentase produktivitas tenaga kerja di Indonesia adalah 74,4\%. Tingkat produktivitas ini lebih rendah dari rata-rata Perhimpunan Bangsa-Bangsa Asia Tenggara (ASEAN) yaitu 78,2\% (Azizah, 2020).

Berdasarkan data CEIC pertumbuhan produktivitas diperbarui setiap tahun. Pada Gambar 1 produktivitas tenaga kerja Indonesia menurun sebesar 3,01\% pada Desember 2019. Data tersebut mencapai titik tertinggi sepanjang masa sebesar 5,56\% pada Desember 2013 dan rekor terendah 0,78\% pada Desember 2018 (CEIC, 2021).

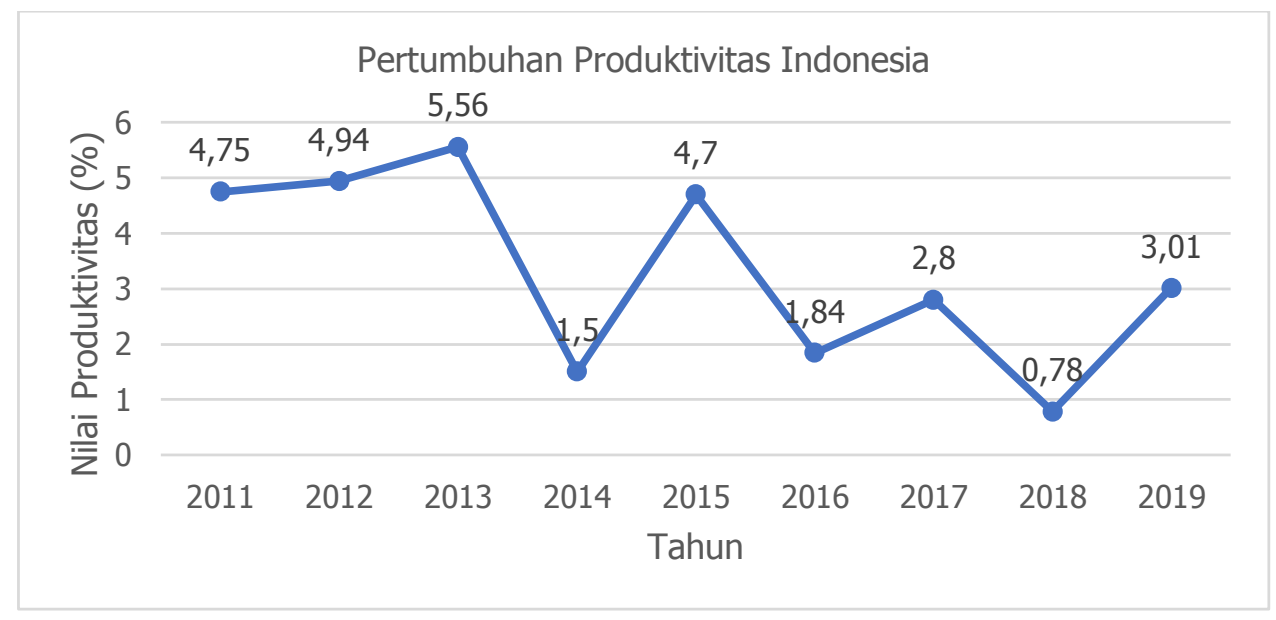

Gambar 1. Pertumbuhan produktivitas Indonesia

Waktu pelaksanaan proyek sering dipercepat untuk memenuhi jadwal penyelesaian pekerjaan konstruksi. Salah satu cara untuk mempercepat durasi proyek adalah dengan menerapkan jam kerja lembur. Lembur lebih sering dipilih karena tidak menimbulkan masalah koordinasi yang yang harus diatasi sebagaimana jika dipakai penambahan tenaga kerja atau pergantian waktu kerja (Sumarningsih, 2014). Kerja lembur harus diimbangi dengan kesiapan faktor pendukung antara lain pekerja, material dan alat kerja yang memenuhi kebutuhan pekerjaan (Sinaga, 2019).

Permasalahan yang akan muncul dalam penelitian ini adalah berapakah tingkat produktivitas konstruksi pada jam kerja normal dan jam kerja lembur serta faktor yang paling mempengaruhi produktivitas lembur dalam pekejaan struktur bawah. Batasan masalah dalam penelitian ini ialah terfokus pada pekerjaan struktur bawah yang meliputi pekerjaan pondasi tiang pancang dan capping beam. 
Tujuan utama yang ingin dicapai dalam penelitian ini adalah untuk mengetahui nilai produktivitas pekerja di jam kerja normal dan lembur pada struktur bawah serta untukmengetahui dan mengidentifikasi faktor-faktor yang mempengaruhi produktivitas kerja lembur dalam pekerjaan struktur bawah yang meliputi pekerjaan pemancangan dan pekerjaan capping beam.

Manfaat yang diharapkan penulis pada penelitian ini mampu menambah wawasan dalam pekerjaan di lapangan, serta menjadi masukan kepada PT. X mengenai perbandingan produktivitas pada jam kerja normal dan lembur serta mengetahui faktor dominan yang mempengaruhi dalam pekerjaan struktur bawah. Kelak penelitian ini diharapkan mampu menjadi pedoman dalam penelitian yang berkaitan lainnya.

\section{TINJAUAN PUSTAKA}

\subsection{Kerja Lembur (Overtime)}

Di Indonesia, Kementrian Tenaga Kerja yang mengatur mengenai kerja lembur yang tertuang dalam peraturan No.KEP.102/MEN/VI/2004 menyatakan bahwa lembur dilaksanakan maksimal 3 jam per hari dan 14 jam per minggu dan tidak berlaku lembur pada hari minggu dan pada hari libur resmi (Ernala, 2018).

Defisi lembur tertuang dalam Pasal 1 Nomor Kep 102/MEN/VI/2004, yaitu:

1. Jam kerja melebihi 40 jam per minggu untuk 6 hari kerja, dan melebihi 7 jam per hari.

2. Jam kerja 8 jam per hari dan 40 jam per minggu untuk 5 hari kerja.

3. Jam kerja di akhir pekan dan hari libur.

Namun, ini tidak berlaku untuk pekerja yang termasuk dalam kelompok pekerjaan tertentu. Dengan kata lain, pekerja tidak berhak atas lembur karena menerima upah yang tinggi. Tenaga kerja dari kelompok pekerjaan tertentu yang bertanggung jawab untuk memikirkan, merencanakan, melaksanakan dan mengelola perusahaan tidak boleh membatasi jam kerjanya sesuai dengan kerangka waktu kerja yang ditetapkan oleh perusahaan berdasarkan undangundang dan peraturan terkait (Kemenakertrans, 2004).

\subsection{Produktivitas}

Produktivitas adalah hubungan antara output dan input, atau hasil dari produktivitas beban kerja dan sumber daya yang dikerjakan (Ervianto, 2005), dapat dirumuskan pada Persamaan 1 berikut.

$$
\text { Produktivitas }=\frac{\text { Output }}{\text { Input }}
$$

Untuk menentukan peringkat faktor-faktor yang mempengaruhi produktivitas pada proyek X, digunakan perhitungan dengan metode Relative Importance Index (RII) yang diolah berdasarkan kepentingan dari informan, skala yang digunakan 1 sampai 5 yang berarti angka 1 mewakili kategori kurang berpengaruh dan 5 untuk pernyataan yang sangat berpengaruh (Ardiyawan, R., Purwanggono, B., \& Handayani, 2019), dapat dirumuskan pada Persamaan 2 berikut.

$$
\text { Relative Importance Index }=\frac{5(\mathrm{n} 5)+4(\mathrm{n} 4)+3(\mathrm{n} 3)+2(\mathrm{n} 2)+1(\mathrm{n} 1)}{5(\mathrm{n} 5+\mathrm{n} 4+\mathrm{n} 3+\mathrm{n} 2+\mathrm{n} 1)}
$$

Indeks produktivitas digunakan dalam mengukur dan mengetahui perkembangan apakah unit pekerjan pada perusahaan tersebut memiliki kategori baik atau kurang dalam hal 
produktivitasnya (Cahyani \& Nursin, 2019), Indeks produktivitas secara teknis dapat dinyatakan dalam Persamaan 3 sebagai berikut.

$$
\text { Indeks Produktivitas }=\frac{\text { Produksi Aktual }}{\text { Produksi Rencana }}
$$

Secara umum, beberapa faktor dapat mempengaruhi produktivitas pekerja (Hernandi \& Tamtana, 2020) antara lain:

1. Kualitas dan kuantitas pekerja yang digunakan untuk melaksanakan pekerjaan konstruksi.

2. Tingkat keterampilan pekerja.

3. Tingkat pendidikan pekerja dan lingkungan.

4. Kemampuan tenaga kerja dalam menganalisis kondisi yang dihadapi.

5. Minat kerja pekerja.

6. Struktur kerja (jenis kelamin dan usia).

\section{METODE PENELITIAN}

\subsection{Lokasi dan Objek Penelitian}

Lokasi penelitian dilakukukan pada proyek X, objek penelitian merupakan struktur bawah pada pekerjaan pondasi tiang pancang dan capping beam yang meliputi pekerjaan pembesian, bekisting dan pengecoran.

\subsection{Metode Pengumpulan Data}

Pengumpulan data merupakan studi lapangan yang secara langsung menganalisis organisasi/sektor dari mana data primer dan sekunder akan dikumpulkan. Sumber primer merupakan data yang diberikan secara langsung kepada penulis (Sugiyono, 2012).

Data primer penelitian ini didapatkan melaului metode survei menggunakan teknik pengambilan sampel secara purposive random sampling dengan pertimbangan keterwakilan dari jumlah total tenaga kerja yang akan dianalisa menggunakan metode Relative Inportance Index yang didapatkan dari hasil kuesioner oleh peneliti secara langsung dari sumber data (Amalia et al., 2021).

Berikut merupakan rincian dari pembagian kuesioner kepada responden serta jumlah hasil pengembalian dari kuesioner.

Tabel 1. Kelompok Responden dan Jumlah Pengembalian Kuesioner

\begin{tabular}{|c|c|c|c|}
\hline \multirow{2}{*}{ Parameter } & \multicolumn{2}{|c|}{ Jumlah Kuesioner } & \multirow{2}{*}{$\begin{array}{c}\text { Presentase } \\
{[\%]}\end{array}$} \\
\hline & Disebar & Kembali & \\
\hline PT. X & 4 & 4 & 100 \\
\hline PT. Y & 3 & 3 & 100 \\
\hline PT. Z & 1 & 1 & 100 \\
\hline Pekerja & 22 & 22 & 100 \\
\hline
\end{tabular}

Dari Tabel 1 didapat 30 responden yang terbagi dalam konsultan MK, kontraktor, owner dan tenaga kerja yang terlibat di lapangan. Selanjutnya data diolah menggunakan bantuan Microsoft Excel 2016 untuk mengetahui faktor yang paling mempengaruhi produktivitas pada pekerjaan struktur bawah. 
Pengamatan untuk mengetahui produktivitas tenaga kerja pada jam normal dan lembur dalam pekerjaan struktur bawah dilakukan secara langsung yang dimulai pada pukul 08.00-17.00 (untuk jam kerja normal, dengan istrirahat satu jam) serta dilanjutkan pengamatan pada pukul 19.00-22.00 (untuk jam kerja lembur). Berikutnya data yang diperoleh diolah dengan menggunakan Persamaan 1.

Data sukunder didapatkan dari proyek melalui bagian administrasi MK berupa volume pekerjaan dan penjadwalan yang digunakan untuk mengetahui produksi rencana dalam pehitungan analisis indeks produktivitas.

\section{HASIL DAN PEMBAHASAN}

\subsection{Produktivitas Tenaga Kerja Struktur Bawah}

\subsubsection{Pekerjaan Pondasi Tiang Pancang}

Dari Tabel 2 didapat produktivitas rata-rata tenaga kerja pondasi tiang pancang dijam normal sebesar 3,486 m'/manhours. Sedangkan di waktu lembur produktivitas rata-rata sebesar 3,962 $\mathrm{m}$ '/manhours.

Tabel 2. Volume Pekerjaan Pondasi Tiang Pancang

\begin{tabular}{cccc}
\hline \multirow{2}{*}{ Tanggal } & \multirow{2}{*}{ Tenaga Kerja } & \multicolumn{2}{c}{ Volume [m'] } \\
\cline { 3 - 4 } & & Normal & Lembur \\
\hline $25 / 03 / 2021$ & 6 & 160 & 64 \\
\hline $26 / 03 / 2021$ & 6 & 160 & 80 \\
\hline $27 / 03 / 2021$ & 6 & 144 & 64 \\
\hline $28 / 03 / 2021$ & 5 & 144 & 48 \\
\hline $01 / 04 / 2021$ & 6 & 192 & 98 \\
\hline $02 / 04 / 2021$ & 6 & 160 & 80 \\
\hline Jumlah & 35 & 976 & 416 \\
\hline \multicolumn{2}{c}{ Produktivitas $\left[\mathrm{m}^{\prime} / \mathrm{OH}\right]$} & 27,886 & 11,886 \\
\hline
\end{tabular}

\subsubsection{Pekerjaan Capping Beam}

Pekerjaan struktur capping beam ini, mencakup pekerjaan pembesian, bekisting dan pekerjaan pengecoran.

1. Pekerjaan Pembesian

Dari Tabel 3 didapat produktivitas rata-rata tenaga kerja pembesian capping beam dijam normal sebesar $8,545 \mathrm{~m}^{2} /$ manhours. Sedangkan diwaktu lembur produktivitas rata-rata sebesar $12,041 \mathrm{~m}^{2} /$ manhours.

Tabel 3. Volume Pekerjaan Pembesian Capping Beam

\begin{tabular}{cccc}
\hline \multirow{2}{*}{ Tanggal } & \multirow{2}{*}{ Tenaga Kerja } & \multicolumn{2}{c}{ Volume [m'] } \\
\cline { 3 - 4 } & & Normal & Lembur \\
\hline $01 / 04 / 2021$ & 7 & 510,054 & 163,600 \\
\hline $02 / 04 / 2021$ & 7 & 449,104 & 224,552 \\
\hline $03 / 04 / 2021$ & 7 & 421,035 & 252,621 \\
\hline $04 / 04 / 2021$ & 5 & 364,897 & 196,483 \\
\hline $05 / 04 / 2021$ & 5 & 378,931 & 210,517 \\
\hline $06 / 04 / 2021$ & 5 & 336,828 & 252,621 \\
\hline Jumlah & 36 & $2.460,850$ & $1.300,394$ \\
\hline \multicolumn{2}{c}{ Produktivitas $\left[\mathrm{m}^{\prime} / \mathrm{OH}\right]$} & 68,357 & 36,122 \\
\hline
\end{tabular}


2. Pekerjaan Bekisting

Dari Tabel 4 didapat produktivitas rata-rata tenaga kerja bekisting capping beam dijam normal sebesar $0,452 \mathrm{~kg} /$ manhours. Sedangkan pada waktu lembur produktivitas ratarata sebesar $0,771 \mathrm{~kg} /$ manhours.

Tabel 4. Volume Pekerjaan Bekisting Capping Beam
\begin{tabular}{|cccc}
\hline \multirow{2}{*}{ Tanggal } & \multirow{2}{*}{ Tenaga Kerja } & \multicolumn{2}{c}{ Volume [m'] } \\
\cline { 3 - 4 } & & Normal & Lembur \\
\hline $05 / 04 / 2021$ & 4 & 15,616 & 7,808 \\
\hline $06 / 04 / 2021$ & 4 & 15,616 & 9,760 \\
\hline $07 / 04 / 2021$ & 4 & 17,568 & 7,808 \\
\hline $08 / 04 / 2021$ & 5 & 15,616 & 11,712 \\
\hline $11 / 04 / 2021$ & 6 & 17,568 & 15,616 \\
\hline $12 / 04 / 2021$ & 5 & 15,616 & 9,760 \\
\hline Jumlah & 27 & 97,600 & 62,464 \\
\hline \multicolumn{2}{c}{ Produktivitas $\left[\mathrm{m}^{\prime} / \mathrm{OH}\right]$} & 3,615 & 2,313 \\
\hline
\end{tabular}

3. Pekerjaan Pengecoran

Dari Tabel 5 didapat rata-rata produktivitas pekerja pengecoran capping beam dijam normal sebesar $0,168 \mathrm{~m}^{3} /$ manhours. Pekerjaan pengecoran ini hanya dilakukan pada jam kerja normal, hal ini di karenakan oleh dampak sosial di proyek tersebut. Warga perumahan Bumi Karang Indah tidak mengizinkan pekerjaan pengecoran di malam hari.

Tabel 5. Volume Pekerjaan Pengecoran Capping Beam

\begin{tabular}{cccc}
\hline \multirow{2}{*}{ Tanggal } & \multirow{2}{*}{ Tenaga Kerja } & \multicolumn{2}{c}{ Volume [m'] } \\
\cline { 3 - 4 } & & Normal & Lembur \\
\hline $06 / 04 / 2021$ & 4 & 5 & - \\
\hline $07 / 04 / 2021$ & 4 & 5 & - \\
\hline $10 / 04 / 2021$ & 6 & 7 & - \\
\hline $11 / 04 / 2021$ & 4 & 6,5 & - \\
\hline $12 / 04 / 2021$ & 4 & 6 & - \\
\hline Jumlah & 27 & 29,5 & - \\
\hline \multicolumn{2}{c}{ Produktivitas $\left[\mathrm{m}^{\prime} / \mathrm{OH}\right]$} & 1,314 & - \\
\hline
\end{tabular}

\subsection{Analisis Indeks Produktivitas}

\subsubsection{Pekerjaan Pondasi Tiang Pancang}

Produksi aktual pada pekerjaan pondasi tiang pancang adalah $232 \mathrm{~m} /$ hari; sedangkan untuk produksi rencana sebesar 197,6 m'/hari (PT. Tethagrha Adyatama, 2021); maka didapatkan:

$$
\text { Indeks Produktivitas }=\frac{\text { Produksi Aktual }}{\text { Produksi Rencana }}=\frac{232}{197,6}=1,17
$$

Angka 1,17 > 1; maka produktivitas pekerjaan pondasi tiang pancang dikatakan baik.

\subsubsection{Pekerjaan Pembesian Capping Beam}

Produksi aktual pada pekerjaan pembesian capping beam adalah 626,873 kg/hari, sedangkan untuk produksi rencana sebesar $421 \mathrm{~kg} /$ hari maka didapatkan:

$$
\text { Indeks Produktivitas }=\frac{\text { Produksi Aktual }}{\text { Produksi Rencana }}=\frac{626,243}{197,6}=1,48
$$

Angka 1,48 > 1; maka produktivitas pekerjaan pembesian capping beam dikatakan baik. 


\subsubsection{Pekerjaan Bekisting Capping Beam}

Produksi aktual pada pekerjaan pembesian capping beam adalah $26,677 \mathrm{~m}^{2} /$ hari, sedangkan untuk produksi rencana sebesar $24 \mathrm{~m}^{2} /$ hari maka didapatkan:

$$
\text { Indeks Produktivitas }=\frac{\text { Produksi Aktual }}{\text { Produksi Rencana }}=\frac{26,677}{24}=1,11
$$

Angka $1,11>1$; maka produktivitas pekerjaan bekisting capping beam dikatakan baik.

\section{.2.4 Pekerjaan Pengecoran Capping Beam}

Produksi aktual pada pekerjaan pengecoran capping beam adalah $5,9 \mathrm{~m}^{3} /$ hari, sedangkan untuk produksi rencana sebesar $7 \mathrm{~m}^{3} /$ hari maka didapatkan:

$$
\text { Indeks Produktivitas }=\frac{\text { Produksi Aktual }}{\text { Produksi Rencana }}=\frac{5,9}{7}=0,84
$$

Angka $0,84<1$; maka produktivitas pekerjaan pengecoran capping beam dikatakan kurang baik.

\subsection{Faktor-faktor yang Paling Berpengaruh terhadap Produktivitas Lembur Tenaga Kerja Konstruksi}

Berdasarkan kuesioner yang sudah disebar dan hasil perhitungan menggunakan metode Relative Importance Index, sepuluh faktor-faktor yang mempengaruhi produktivitas pekerjaan struktur bawah tersebut adalah sebagai berikut.

1. Faktor Lingkungan

Pada saat keadaan hujan, proses pelaksanaan pekerjaan tidak dapat berjalan karena site kerja menjadi basah dan licin. Kondisi site kerja tersebut dapat membahayakan keselamatan pekerja. Hal tersebut mempengaruhi produktivitas pekerja. Sehingga, tingkat produktivitas dari tenaga kerja dapat menurun. Hal ini ditunjukkan Tabel 6.

Tabel 6. Hasil Kuesioner X7.1

\begin{tabular}{ccc}
\hline X7.1 & Frekuensi & Frekuensi Kumulatif \\
\hline Sangat tidak setuju & - & - \\
\hline Tidak setuju & 1 & 1 \\
\hline Ragu-ragu & 1 & 2 \\
\hline Setuju & 2 & 4 \\
\hline Sangat setuju & 26 & 30 \\
\hline
\end{tabular}

2. Faktor Lingkungan

Pada saat site kerja rapih, proses pelaksanaan pekerjaan dapat berjalan dengan baik dan lancar dan mampu menghasilkan progres pekerjaan yang tepat waktu. Sebaliknya jika kondisi site kerja tidak rapih akan mengasilkan pekerjaan yang tidak tepat waktu dan dapat mempengaruhi produktivitas pekerja. Sehingga, tingkat produktivitas dari tenaga kerja dapat menurun. Hal ini terjadi karena site kerja yang tidak rapih dapat memperlambat pekerjaan di lapangan. Hal ini ditunjukkan Tabel 7.

Tabel 7. Hasil Kuesioner X7.2

\begin{tabular}{ccc}
\hline $\mathbf{X 7 . 2}$ & Frekuensi & Frekuensi Kumulatif \\
\hline Sangat tidak setuju & - & - \\
\hline Tidak setuju & - & - \\
\hline Ragu-ragu & 1 & 1 \\
\hline Setuju & 18 & 19 \\
\hline Sangat setuju & 11 & 30 \\
\hline
\end{tabular}


3. Pengalaman Kerja

Pengalaman pekerja bekerja lebih dari 7 kali di bidang konstruksi mempengaruhi produktivitas tenaga kerja tersebut. Hal ini menunjukkan bahwa semakin banyak nya pengalaman bekerja maka semakin tinggi kinerja SDM-nya. Hal ini ditunjukkan Tabel 8.

Tabel 8. Hasil Kuesioner X2.1

\begin{tabular}{ccc}
\hline X2.1 & Frekuensi & Frekuensi Kumulatif \\
\hline Kurang dari 2 kali & 1 & 1 \\
\hline 2-3 kali & - & 1 \\
\hline 4-5 kali & 4 & 5 \\
\hline 6-7 kali & 9 & 14 \\
\hline Lebih dari 7 kali & 16 & 30 \\
\hline
\end{tabular}

4. Metode Kerja

Metode kerja yang digunakan tidak menyulitkan para pekerja. Hal tersebut mempengaruhi performa dan produktivitas pekerja, apabila metode kerja yang digunakan kurang tepat maka produktivitas dari tenaga kerja dapat menurun. Hal ini ditunjukkan Tabel 9.

Tabel 9. Hasil Kuesioner X8.1

\begin{tabular}{ccc}
\hline $\mathbf{X 8 . 1}$ & Frekuensi & Frekuensi Kumulatif \\
\hline Sangat tidak setuju & 1 & 1 \\
\hline Tidak setuju & - & - \\
\hline Ragu-ragu & 4 & 5 \\
\hline Setuju & 10 & 15 \\
\hline Sangat setuju & 15 & 30
\end{tabular}

5. Faktor Lingkungan

Penempatan alat dan bahan kerja yang sesuai, dapat mempercepat pekerjaan karena tidak menghalangi site kerja. Apabila penempatan alat dan bahan kerja yang tidak sesuai, dapat menyulitkan para pekerja. Hal tersebut mempengaruhi performa dan produktivitas pekerja. Hal ini ditunjukkan Tabel 10.

Tabel 10. Hasil Kuesioner X7.3

\begin{tabular}{ccc}
\hline $\mathbf{X 7 . 3}$ & Frekuensi & Frekuensi Kumulatif \\
\hline Sangat tidak setuju & 1 & 1 \\
\hline Tidak setuju & - & - \\
\hline Ragu-ragu & 4 & 5 \\
\hline Setuju & 10 & 15 \\
\hline Sangat setuju & 15 & 30 \\
\hline
\end{tabular}

6. Keselamatan Kerja

Penerangan proyek yang cukup ini mempengaruhi besarnya produktivitas. Hal tersebut dikarenakan apabila proyek memiliki penerangan yang cukup, tidak terlalu gelap dan tidak terlalu terang, maka dapat memudahkan dalam pekerjaan. Sehingga, tingkat produktivitas dari tenaga kerja dapat terjaga. Hal ini ditunjukkan Tabel 11. 
Tabel 11. Hasil Kuesioner X6.2

\begin{tabular}{ccc}
\hline $\mathbf{X 6 . 2}$ & Frekuensi & Frekuensi Kumulatif \\
\hline Sangat tidak setuju & - & - \\
\hline Tidak setuju & - & - \\
\hline Ragu-ragu & 4 & 4 \\
\hline Setuju & 18 & 22 \\
\hline Sangat setuju & 8 & 30 \\
\hline
\end{tabular}

7. Metode Kerja

Metode yang sesuai SOP dapat meningkatankan performa pekerja, sehingga nilai produktivitasnya akan naik. Sebaliknya, jika pemilihan metode yang tidak sesuai SOP akan mempersulit tenaga kerja sehingga segingga berdampak dengan penurunan produktivitas pekerja. Hal ini ditunjukkan Tabel 12.

Tabel 12. Hasil Kuesioner X8.2

\begin{tabular}{ccc}
$\mathbf{X 8 . 2}$ & Frekuensi & Frekuensi Kumulatif \\
\hline Sangat tidak setuju & 1 & 1 \\
\hline Tidak setuju & - & 1 \\
\hline Ragu-ragu & 5 & 6 \\
\hline Setuju & 13 & 19 \\
\hline Sangat setuju & 11 & 30 \\
\hline
\end{tabular}

8. Material dan Alat

Peralatan yang sesuai permintaan dan kebutuhan mampu meningkatankan performa pekerja, sehingga nilai produktivitasnya cenderung stabil bahkan naik. Sebaliknya, jika penggunaan peralatan yang tidak sesuai akan mempersulit tenaga kerja sehingga akan berdampak dengan penurunan produktivitas pekerja. Hal ini ditunjukkan Tabel 13.

Tabel 13. Hasil Kuesioner X4.4

\begin{tabular}{ccc}
$\mathbf{X 4 . 4}$ & Frekuensi & Frekuensi Kumulatif \\
\hline Sangat tidak setuju & - & - \\
\hline Tidak setuju & - & - \\
\hline Ragu-ragu & 5 & 5 \\
\hline Setuju & 18 & 23 \\
\hline Sangat setuju & 7 & 30 \\
\hline
\end{tabular}

9. Material dan Alat

Material yang sesuai permintaan dan kebutuhan mampu meningkatankan performa pekerja, sehingga nilai produktivitasnya cenderung stabil bahkan naik. Sebaliknya, jika penggunaan material yang tidak sesuai akan mempersulit tenaga kerja sehingga akan berdampak dengan penurunan produktivitas. Hal ini ditunjukkan Tabel 14.

Tabel 14. Hasil Kuesioner X4.3

\begin{tabular}{ccc}
\hline $\mathbf{X 4 . 3}$ & Frekuensi & Frekuensi Kumulatif \\
\hline Sangat tidak setuju & - & - \\
\hline Tidak setuju & - & - \\
\hline Ragu-ragu & 6 & 6 \\
\hline Setuju & 16 & 24 \\
\hline Sangat setuju & 7 & 30 \\
\hline
\end{tabular}

10. Material dan Alat 
Penyediaan alat/mesin konstruksi yang tepat waktu dan sesuai dengan tingkat efesiensinya mampu meningkatankan performa pekerja, sehingga nilai produktivitasnya cenderung stabil bahkan naik. Sebaliknya, Penyediaan alat/mesin konstruksi yang tidak tepat waktu dan kurang sesuai dengan tingkat efesiensinya akan mempersulit tenaga kerja sehingga akan berdampak dengan penurunan produktivitas pekerja. Hal ini ditunjukkan Tabel 15.

Tabel 15. Hasil Kuesioner X4.2

\begin{tabular}{ccc}
\hline $\mathbf{X 4 . 2}$ & Frekuensi & Frekuensi Kumulatif \\
\hline Sangat tidak setuju & - & - \\
\hline Tidak setuju & 1 & 1 \\
\hline Ragu-ragu & 4 & 5 \\
\hline Setuju & 22 & 27 \\
\hline Sangat setuju & 3 & 30 \\
\hline
\end{tabular}

Berikut merupakan perhitungan Relative Importance Indexyang berisi sepuluh besar faktor yang paling mempengaruhi kerja lembur terhadap produktivitas pekerjaan struktur bawah. Hal ini ditunjukkan Tabel 16.

Tabel 16. Peringkat Dari Masing-masing Faktor

\begin{tabular}{cccc}
\hline \multicolumn{1}{c}{ Variabel } & Indikator & Nilai RII & Peringkat \\
\hline Faktor lingkungan & Kondisi cuaca lokasi kerja & 95,33 & 1 \\
\hline Faktor lingkungan & Site kerja yang rapi & 86,67 & 2 \\
\hline Pengalaman kerja & Pengalaman kerja & 86,00 & 3 \\
\hline Metode kerja & Metode kerja yang digunakan & 85,33 & 4 \\
\hline Faktor lingkungan & Penempatan peralatan dan bahan & 84,00 & 5 \\
\hline Keselamatan kerja & Penerangan proyek & 82,67 & 6 \\
\hline Metode kerja & Kesesuaian merode dengan SOP & 82,00 & 7 \\
\hline Material dan alat & Kesesuaian peralatan dengan permintaan & 81,33 & 8 \\
\hline Material dan alat & Kesesuaian material dengan permintaan & 80,00 & 9 \\
\hline Material dan alat & Ketepatan waktu alat/mesin & 78,00 & 10 \\
\hline
\end{tabular}

\section{KESIMPULAN}

Produktivitas pekerjaan tiang pancang jam normal 3,489 $\mathrm{m} /$ manhours dan 3.941 $\mathrm{m}$ '/manhours jam lembur; produkivitas pekerjaan pembesian capping beam pada jam normal $8,610 \mathrm{~kg} /$ manhours dan $12,415 \mathrm{~kg} /$ manhours jam lembur, pekerjaan bekisting jam normal $0,462 \mathrm{~m}^{2} /$ manhours dan 0,763 $\mathrm{m}^{2} /$ manhours jam lembur, pekerjaan pengecoran normal 0,170 $\mathrm{m}^{3} /$ manhours. Performa proyek dihitung dengan rumus indeks produktivitas dan menghasilkan angka > 1 yang artinya performa proyek cukup baik, sedangkan pada pekerjaan pengecoran memiliki performa yang kurang baik karena nilai indeks produktivitas $<1$. Hasil kuesioner menggunakan metode Relative Importance Index didapatkan sepuluh faktor yang mempengaruhi produktivitas lembur pada pekerjaan struktur bawah, diantaranya variabel faktor lingkungan, pengalaman kerja, metode kerja, keselamatan kerja dan variabel material dan alat. 


\section{UCAPAN TERIMA KASIH}

Penulis mengucapkan terima kasih kepada UP2M Politeknik Negeri Jakarta yang telah memberikan bantuan dana sehingga penelitian ini dapat berjalan dengan lancar.

\section{DAFTAR PUSTAKA}

Amalia, A. et al. (2021) 'Perception Analysis Of PNJ Civil Engineering Students Toward Main Course Using Importance', Pedagogia: Jurnal Pendidikan., 10(1), pp. 61-78. doi: 10.21070/pedagogia.v10vi1i.1.

Ardiyawan, R, Purwanggono, B, \& Handayani, N. U. (2019) 'Penilaian Dan Mitigasi Risiko Berupa Tindakan Preventif Dan Recovery Pada Proyek Pembangunan Jalan Tol.', Industrial Engineering Online Journal, vol. 7, no. 4, Jan. 2019, 4(1), p. 11. Available at: https://ejournal3.undip.ac.id/index.php/ieoj/article/view/23053.

Azizah, N. (2020) Produktivitas Tenaga Kerja Indonesia di Bawah Rata-rata ASEAN. Available at:https://www.medcom.id/nasional/politik/GNlq60gb-produktivitas-tenaga-kerjaindonesia-di-bawah-rata-rata-asean.

Cahyani, A. P. and Nursin, A. (2019) 'Analisis Produktivitas Tenaga Kerja Pada Pekerjaan Dinding Proyek Tamansari Iswara Apartment', Seminar Nasional Teknik Sipil Politeknik Negeri Jakarta.

CEIC (2021) Indonesia Labour Productivity Growth, https://www.ceicdata.com.

Deni, R. (2020) Ma'ruf Amin Sebut Produktivitas Tenaga Kerja Indonesia Bukan yang Terbaik di ASEAN, https://www.tribunnews.com. Available at: https://www.tribunnews.com/nasional/2020/07/21/maruf-amin-sebut-produktivitastenaga-kerja-indonesia-bukan-yang-terbaik-di-asean.

Ernala, A. (2018) Analisis Perbandingan Produktivitas Kerja Normal dan Lembur (Studi Kasus: Proyek Pembangunan Apartemen The Wahid Residences. Universitas Sumatera Utara.

Ervianto, W. I. (2005) Manajemen proyek konstruksi. Yogyakarta: Andi.

Hasanah, N. et al. (2017) 'KONSTRUKSI ANTARA JAM KERJA NORMAL DENGAN JAM KERJA LEMBUR DI KOTA PADANG', Prosiding 4th Andalas Civil Engineering (ACE) Conference 2017, Prosiding(November), pp. 21-32.

Hernandi, Y. and Tamtana, J. S. (2020) 'Faktor-Faktor Yang Mempengaruhi Produktivitas Pekerja Pada Pelaksanaan Konstruksi Gedung Bertingkat', JMTS: Jurnal Mitra Teknik Sipil, 3(2), p. 299. doi: 10.24912/jmts.v3i2.6985.

Kemenakertrans (2004) Keputusan Menteri Tenaga Kerja dan Transmigrasi Republik Indonesia. Indonesia.

PT. Tethagrha Adyatama (2021) Data Proyek Apartemen Apple 3 Condovilla. Jakarta.

Sinaga, A. S. R. (2019) 'Penentuan Karyawan Lembur Dengan Metode Analytical Hierarchy Process (Ahp)', Jurnal Inkofar, 1(2), pp. 40-50. doi: 10.46846/jurnalinkofar.v1i2.67.

Sugiyono (2012) Memahami Penelitian Kualitatif. BANDUNG: ALFABETA.

Sumarningsih, T. (2014) 'Pengaruh Kerja Lembur pada Produktivitas Tenaga Kerja Konstruksi', MEDIA KOMUNIKASI TEKNIK SIPIL, VOLUME 20, pp. 63-69. 